\title{
EMEA and Gene Therapy Medicinal Products Development in the European Union
}

\author{
Marisa Papaluca Amati, ${ }^{\dagger \dagger}$ Francesco Pignatti, Alexis Nolte, Nirosha Amerasinghe, \\ Daniel Gustafsson, Isabelle Moulon, and Patrick Le Courtois \\ The European Agency for the Evaluation of Medicinal Products, \\ 7 Westferry Circus, Canary Wharf, London E14 4HB, UK
}

Received 9 August 2002; accepted 19 August 2002

\begin{abstract}
The evaluation of quality, safety, and efficacy of medicinal products by the European Medicines Evaluation Agency (EMEA) via the centralized procedure is the only available regulatory procedure for obtaining marketing authorization for gene therapy (GT) medicinal products in the European Union. The responsibility for the authorization of clinical trials remains with the national competent authorities (NCA) acting in a harmonized framework from the scientific viewpoint. With the entry into force of a new directive on good clinical practice implementation in clinical trials as of 1 May 2004, procedural aspects will also be harmonized at EU level. Scientifically sound development of medicinal products is the key for the successful registration of dossiers and for contributing to the promotion and protection of public health. The objective of this paper is to introduce the EMEA regulatory processes and scientific activities relevant to GT medicinal products.
\end{abstract}

\section{INTRODUCTION TO THE EMEA AND THE EU MEDICINES NETWORK}

The legal basis for the operation of the EMEA (European Medicines Evaluation Agency) was established by the Council Regulation 2309/EC adopted by the European Council of Ministers [1] in July 1993.

The main objective of the EMEA mission is to contribute to the protection and promotion of public and animal health by

(i) mobilizing scientific resources from throughout the European Union to provide high quality evaluation of medicinal products, to advise on research and development programmes and to provide useful and clear information to users and health professionals;

(ii) developing efficient and transparent procedures to allow timely access, by users, to innovative medicines through a single European marketing authorization;

(iii) controlling the safety of medicines for humans and animals, in particular through a pharmacovigilance network and the establishment of safe limits for residues in food-producing animals.

The EMEA is a technical agency acting as a central point of coordination of the existing scientific resources in the European Union (EU) for the regulatory and scientific evaluation of medicinal products both for human and veterinary use $[2,3,4]$. The operations started in January 1995. The main tasks carried out by the EMEA can be grouped in three categories:
(1) regulatory and scientific contribution to the life cycle of medicinal products,

(2) harmonization of technical requirements for marketing authorization at EU and international level,

(3) support to the European Commission on policy matters relevant to medicinal products.

Moreover, the agency is responsible for the efficient running of the operations at EU level including development and maintenance of the necessary IT tools (such as databases) and networks to support the communication and coordination among the stakeholders.

New legislation adopted since 1995 has added a number of responsibilities, in the context of orphan designation, with the creation of the Committee for Orphan Medicinal Products (COMP) [5]. Other tasks relate to the conduct of clinical trials, as well as pharmacovigilance activities for medicines for veterinary and for human use, including the design and the operating of various systems, such as a clinical trial database and the EudraVigilance database for the transmission of adverse drug reactions $[7,8]$.

The scientific competences of the EMEA on medicines for human use, are based within its scientific committees, the Committee for Proprietary Medicinal Products (CPMP), which is responsible for evaluating quality, safety, and efficacy and the COMP, which is responsible 
for the evaluation of requirements for the designation of the orphan medicinal product status.

\section{THE EMEA IN THE LIFE CYCLE OF GENE THERAPY MEDICINAL PRODUCTS}

\section{Regulatory framework}

Whilst the EMEA has no remit for the authorization of the conduct of clinical trials in the EU, it is agreed that a scientifically sound development is necessary in order to demonstrate the efficacy of the product and to exclude any major safety problem incompatible with the safe use of the product.

GT products must be authorized through the centralized procedure [1]. The application for marketing authorization (MA) must be made to the EMEA as described in the Notice to Applicants [9]. At the conclusion of the scientific evaluation undertaken in 210 days, the opinion of the scientific committee is transmitted to the European Commission to be transformed into a single marketing authorization applying to the whole European Union.

At present, the presentation of the MA application dossier for GT products must fulfil the same administrative and scientific requirements as for any other medicinal product as laid down in the legislation [6]. These include requirements relating to establishments, in which GT medicinal products are manufactured [10], and considerations on the environmental impact of the use of gene transfer products on the deliberate release of genetically modified microorganisms. At the level of marketing authorization applications, the CPMP will ensure that all appropriate measures are taken to avoid adverse effects on human health of the environment, which might arise from the deliberate release of placing on the market genetically modified organisms (eg, genetically modified viruses acting as gene transfer vectors).

The environmental impact of the use of gene transfer products as far as their contained use is concerned, has implications for the authorization and conduct of clinical trials as they may present biosafety issues related to intrinsic safety properties and also the safe handling in relation to environments and the wider human population. These aspects are taken into consideration by the competent authorities in member states when authorizing the conduct of clinical trials.

\section{Guidelines and scientific advice}

Technical requirements useful for scientifically sound development of GT products are established at EU level as reference tool not only for sponsors but also for the bodies in charge of the authorization for conducting clinical trials within the member states, and for the final premarketing regulatory evaluations.

One of the tasks of the EMEA is to advise companies on the conduct of the various tests and trials necessary to demonstrate the quality, safety, and efficacy of medicinal products.
The advice is generally given in the form of guidelines or scientific advice on individual products. The guidelines are produced with the support of specific CPMP working groups, such as the Biotechnology Working Party, the Safety Working Party, the Efficacy Working Party, and the ad hoc group on GT. Relevant guidance documents are also produced within the framework of the International Conference for Harmonization (ICH) — see "Future Developments" section.

Since gene transfer products contain genetic and other materials of biological origin, many of the quality considerations for recombinant DNA (rDNA) products and other biologicals manufactured by modern biotechnological methods will apply to the manufacture of gene transfer products.

Biotechnology guidelines are made available on the EMEA web page, http://www.emea.eu.int.

In order to address the specificities of GT, the CPMP has developed a multidisciplinary note for guidance, which was adopted in April 2001 [11]. The objective of the CPMP note for guidance is to provide recommendations and assistance in generating data on quality, nonclinical, and clinical aspects of gene transfer medicinal products, intended to support marketing authorization applications within the European Union. The current version maintains the focus on general aspects whereas guidance on specific therapeutic applications is addressed in other relevant documents. Experts regularly involved at national level in the evaluations concerning the clinical trials authorization, provide the scientific contribution on the issuance of such guidelines. Further input from interested parties is then provided during the consultation period, which is the usual procedure undertaken by the EMEA before finalising the regulatory recommendations.

As for any new technology, a flexible approach for the control of these products is being adopted so that recommendations can be modified in the light of experience gained from production and use, and from further developments.

Whilst the recommendations set out in the GT guideline should be considered to be generally applicable, individual products may present specific quality control and safety concerns, for example, as in the case of DNA vaccines intended for prophylactic use in a large number of healthy individuals.

The production and control of each product will be considered on a case-by-case or product-specific basis reflecting the intended clinical use of the product.

As regulatory experience with this treatment modality is still growing, in order to address product specific issues and more generally scientific issues not covered by or deviating from existing guidance, the CPMP is able to provide Scientific Advice to Applicants on quality, nonclinical and clinical aspects of their development program. The CPMP scientific advice is made available to the sponsors on request. The scientific advice is not binding for the sponsor or for the CPMP, but deviations from the advice 
may need to be justified and discussed at the time of the evaluation of the dossier for marketing authorization. Details of the procedures are provided on the EMEA web page.

The request for scientific advice may be put forward to the EMEA at any stage in the development of a medicinal product. Presubmission and briefing meetings with the sponsors are also organised at the EMEA to streamline the preparation of the dossier for the available regulatory procedures. So far, out of more than three hundred scientific advices provided on development, four sponsors developing GT products have used this procedure.

This reflects the early stage of development of this innovative approach more often carried out in academic institutions as research initiatives than by the pharmaceutical industry.

The national authorities experts responsible for the approval and supervision of GT provide their input to the EMEA scientific advice process. The authorization of clinical trials in Europe takes place at national level. In the USA, all clinical trials are submitted for central authorization to the FDA through the IND mechanism.

Only very few candidate products have a development plan oriented towards regulatory procedures ultimately leading to the EU-wide issuance of a marketing authorization. Sixteen percent of GT clinical trials are conducted in EU and $80 \%$ in USA; more than $87 \%$ of worldwide GT clinical trials are in an early development (phase I-II) [12].

The GT scientific advices issued so far have addressed specific aspects of phase III clinical trial design, and also the design and adequacy of nonclinical development strategy. The medicinal products concerned were in all cases viral vectors (adenoviral or retroviral vectors) for therapeutic applications in oncology, cardiovascular diseases, rare Mendelian conditions, and infectious diseases.

It is expected that in the future, more requests for scientific advice will be lodged by sponsors, taking into account the potential opened up by the reading and annotation of the human genome, the refinement of vector designs and types and the progress of GT research from the early clinical phase into Phase II-III trials.

\section{Orphan medicinal product designation and procedures}

The EU legislation on orphan medicinal products provides additional support for the development of those GT product intended for the treatment of rare and serious diseases [5]. The EMEA within the COMP has established a procedure for providing the scientific basis for the orphan medicinal products designation [13].

Orphan designation can be obtained for medicinal products intended for human use in specific medical conditions following submission of a valid application to the EMEA. Opinions on orphan medicinal products designations are based on the following cumulative criteria: (i) the seriousness of the condition, (ii) the existence or not of alternative methods of diagnosis, prevention, or treatment, and (iii) either the rarity of the condition (considered to affect not more than five in ten thousand persons in the community) or the insufficient return of development investments.

The EU supports research, development, and marketing of orphan medicinal products, by providing incentives such as protocol assistance and scientific advice from the EMEA, direct access to the Centralized Procedure, fee reduction for centralized applications, priority access to EU research programs, and ten years of market exclusivity from the date of marketing authorization.

So far, three GT medicinal products have been designated as orphan medicinal products and for one of them a protocol assistance process has been initiated in 2002, encompassing scientific advice on development as well as regulatory advice.

Summaries of the designated orphan medicinal products are now made available to the public on the EMEA website as of 2002. The outcomes of the EMEA activities in the field of orphan medicinal products are regularly updated and made available on the EMEA web page within the COMP press releases.

\section{Marketing authorization}

Up to date no marketing authorization has been issued for GT medicinal products.

Under the centralized procedure, applications are made directly to the EMEA, in charge of coordinating the core operations. Independent assessment of the data on quality, safety, and efficacy is carried out by designated evaluation teams located within the national competent authorities. A subsequent scientific peer review process is carried out by the EMEA scientific committees. The outcome of the procedure is a CPMP scientific opinion, which is either favourable or unfavourable. This is communicated to the European Commission, which in turn is responsible for converting CPMP opinions into legally binding decisions (eg, the granting of a marketing authorization in case of a favourable opinion). For every favourable CPMP scientific recommendation to the European Commission on the granting of a marketing authorization, a comprehensive European public assessment report (EPAR) reflecting the scientific review and conclusion of the CPMP is published on the EMEA web page for information to the public. The EPAR excludes commercially confidential information. The outcomes of the EMEA centralized operations since January 1995 till June 2002 are summarized and updated regularly in the CPMP monthly reports and in the annual reports available on the EMEA website.

\section{FUTURE DEVELOPMENTS}

\section{The International Conference on Harmonization of technical requirements for registration of pharmaceuticals and the CPMP GT expert group}

The International Conference on Harmonization (ICH) was initiated in April 1990 in Brussels and is a joint 
initiative involving six parties, in scientific discussions of the technical requirements to be satisfied to ensure quality, safety, and efficacy of medicinal products.

The six members of $\mathrm{ICH}$ are the regulatory bodies of the USA (Food and Drug Administration-FDA), EU (European Commission-EMEA), Japan (MHLW), the relevant federations of research based pharmaceutical industry, namely, the Pharmaceutical Research and Manufacturers of America (PhRMA), The European Federation of Pharmaceutical Industry (EFPIA), and the Japanese Pharmaceuticals Manufacturers Association (JPMA). The observers are representatives of the World Health Organisation (WHO), European Free Trade Association (EFTA), and Canada.

The objective of the ICH exercise is to promote international harmonization of the requirements for registration of pharmaceuticals among the three regions EU, USA, and Japan so that medicines are developed and made available in a timely and efficient manner to promote public health, preventing unnecessary duplication of clinical trials in humans, and minimizing the use of animal testing without compromising safety and effectiveness. More information on the ICH activities can be found at the ICH website, http://www.ich.org/ ichlbis.html.

In May 2001, in the context of the ICH, the status of the regulatory guidance documents for GT medicinal products already issued and available in the three regions (EU, USA, and Japan) was discussed.

While there are differences in the format of the documents, the underlying scientific principles are not fundamentally different. For this rapidly evolving area, there is a need to continue fostering the exchange of information amongst the regions particularly in relation to emerging scientific findings, promoting harmonized scientific understanding.

Areas of scientific importance that warrant the attention of ICH as a matter of priority, are the need to review the dose definition and standardization of viral vectors, to facilitate the comparison of dose-related findings in nonclinical studies and to facilitate a better understanding of clinical data.

Of importance is the collaborative work, involving industry, academia, and FDA, that is being conducted at laboratory level to establish wild-type virus reference standard materials for adenovirus Type 5 and adenoassociated virus. A reference standard for a retrovirus is currently available. Plans to develop other standards will be considered. The results of the scientific review on GT standardization approaches and on new emerging GT technology, to be conducted at regional level may be shared in the framework of ICH in the form of scientific workshops. The first one took in September 2002 in Washington DC.

In order to optimize the review of GT developments, the CPMP established and ad hoc expert group on GT. The expert group avails itself of multidisciplinary competence from the CPMP working groups (Biotechnology Working Party, Efficacy Working Party, Safety Working Party, Scientific Advice review group) and external expert on a case-by-case basis depending on the topics on agenda.

The group provides the CPMP with updates on current development in the area of GT research, and gives advice on the trends of such developments, and recommendations for producing technical guidelines in the form of supplementary explanatory notes or position papers when required. The creation of the group was considered important for ensuring that the CPMP guidelines are up-to-date and reflect the state-of-the-art of the technology and to prepare EU scientific positions in such a rapid evolving field.

Within the ICH activities, the group will provide substantial contribution to scientific workshops and public debates.

The scientific reports of the group are made available on the EMEA web page thus keeping the interested public up to date with the EU scientific and regulatory position (eg, http://www.emea.eu.int/pdfs/human/genetherapy/ 584302en.pdf).

\section{EU directive on clinical trials}

The recently approved "GCP directive" addresses a number of fundamental issues relating to the implementation of GCP in clinical trials. The directive is applicable to all clinical trials (phase I-IV) conducted in the EU [14].

Sponsors are required to obtain an authorization from the competent authority of the member state(s) in which the clinical trial is going to be conducted. For most drugs, this can be granted implicitly, if the authority concerned has not informed the sponsor of any grounds for nonacceptance, within a maximum of 60 days. However, written authorization is necessary for trials involving medicinal products intended for GT, somatic cell therapy including xenogenic cell therapy, and all medicinal products containing genetically modified organisms (GMOs). Similarly, whilst ethics committees are required to give a reasoned opinion within a maximum of 60 days for the purpose of commencing a trial, for GT, somatic cell therapy, or medicines containing GMO's, an extension of 30 days will be permitted with a further 90 days in the event of consultation of an expert group. In the case of xenogenic cell therapy, there will be no time limit to the authorization period. No GT trials may be carried out which result in modifications to the subject's germ line genetic identity.

The legislation also establishes the basis for exchange of full information on the conduct of any clinical trial between the national health authorities, the EMEA, and the European Commission through the creation of a comprehensive European clinical trials database.

The GCP directive is about to bring important changes to harmonize the key legal requirements and procedures for conducting clinical trials on medicinal products for human use in the EU. Member states are required 
to implement the directive into national legislation by May 2003 and the directive is to become effective as of 1 May 2004.

\section{CONCLUSIONS}

During the first seven years of EMEA operation (1995-2002), a number of initiatives have been set up in order to facilitate the dialogue on the development of medicines, and to streamline relevant regulatory procedures.

Only a very limited number of GT medicinal products have been submitted through the EU network and this reflects from one side the ongoing efforts in research, and on the other side the status of early development in the clinical applications of GT. Scientific advice has been provided for GT products intended for the treatment of oncology conditions, immunological disorders, and infectious diseases. The newly established procedure on orphan designation has provided incentives and advice to drug development for rare diseases.

The CPMP has mobilized important scientific resources in order to meet the regulatory challenges of this rapidly evolving field. State-of-the-art scientific advice has been provided on a case-by-case basis. Moreover, in order to keep abreast with the current advances and needs in the GT field, the CPMP has established an ad hoc expert group to provide additional recommendations not only at EU but also at international level. CPMP GT guidelines will be updated or supplemented with explanatory notes to reflect the progress in experience.

On the basis of the exchange of information and experience at ICH level, the group might provide suggestions for future recommendations, position papers, or statements of principle for certain specific topics.

The coming in to force of a new EU legislation to regulate clinical trials authorization and the establishment of the European database for clinical trials are foreseen to provide further opportunities for cooperation in the development of GT medicinal products.

\section{ACKNOWLEDGMENT}

Thanks are due to Susana Soobhujhun for her precious contribution in editing the final paper.

\section{REFERENCES}

[1] Council Regulation (EEC) No 2309/93 of 22 July 1993 laying down Community procedures for the authorisation and supervision of medicinal products for human and veterinary use and establishing a European Agency for the Evaluation of Medicinal Products. Official Journal of the European Communities. 1993;(L 214):1-21.

[2] Sauer F. Europe and medicines: role of the EMEA. Ann Pharm Fr. 2000;58(4):278-285.
[3] Healy EM, Kaitin KI. The European Agency for the Evaluation of Medicinal Product's centralized approach to product approval: current status Drug In J. 1999;33(4):969-978.

[4] European Agency for the Evaluation of Medicinal Products. Seventh Annual Report 2001. Available at: http://www.emea.eu.int/pdfs/general/direct/emeaar/ 005201en.pdf, accessed July 10, 2002.

[5] Regulation (EC) No 141/2000 of the European Parliament and of the Council of 16 December 1999 on orphan medicinal products. Official Journal of the European Communities. 2001;(L 18):1-5.

[6] Directive 2001/83/EC of the European Parliament and of the Council of 6 November 2001 on the Community code relating to medicinal products for human use. Official Journal of the European Communities. 2001;(L 311):67-128.

[7] Commission Directive 2000/37/EC of 5 June 2000 amending Chapter VIa "Pharmacovigilance" of Council Directive 81/851/EEC on the approximation of the laws of the Member States relating to veterinary medicinal products. Official Journal of the European Communities. 2000;(L 139):25-27.

[8] Commission Directive 2000/38/EC of 5 June 2000 amending Chapter Va (Pharmacovigilance) of Council Directive 75/319/EEC on the approximation of provisions laid down by law, regulation or administrative action relating to medicinal products. Official Journal of the European Communities. 2000;(L 139):28-30.

[9] European Commission-Enterprise DG-Pharmaceuticals: Regulatory framework and Market authorisations. Pharmaceutical legislation: Notice to Applicants. The rules governing medicinal products in the European Union. Vol. 2; 2002. Available at: http:// pharmacos.eudra.org/F2/eudralex/vol-2/home.htm, accessed July 10, 2002.

[10] Commission Directive 91/356/EEC, of 13 June 1991, laying down the principles and guidelines of good manufacturing practice for medicinal products for human use. Official Journal of the European Communities. 1991;(L 193):30-33.

[11] Committee for Proprietary Medicinal Products. Note for Guidance on quality, pre-clinical and clinical aspects of gene therapy medicinal products CPMP/BWP/3088/99. 2001. Available at: http:// www.emea.eu.int/pdfs/human/bwp/308899en.pdf, accessed July 10, 2002.

[12] The Journal of Gene Medicine. Gene Therapy Clinical Trials. John Wiley \& Sons; 2001. Available at: http://www.wiley.co.uk/genetherapy/clinical/, accessed July 10, 2002.

[13] European Agency for the Evaluation of Medicinal Products. Procedures for Orphan Medicinal Product Designation-General Principles: EMEA/14222/00. Available at: http://www.emea.eu.int/pdfs/human/ comp/leaflet/661801En.pdf, accessed July 10, 2002. 
[14] Directive 2001/20/EC of the European Parliament and the Council of 4 April 2001 on the approximation of the laws, regulations and administrative provisions of the Member States relating to the implementation of good clinical practice in the conduct of clinical trials on medicinal products for human use. Official Journal of the European Communities. 2001;(L 121):34-44.

* Corresponding author.

E-mail: marisa.papaluca@emea.eu.int

Fax: +44 207418 8613; Tel: +44 2074188436

† The views presented in this article/paper are those of the authors and should not be understood or quoted as being made on behalf of the EMEA and/or its scientific committees 

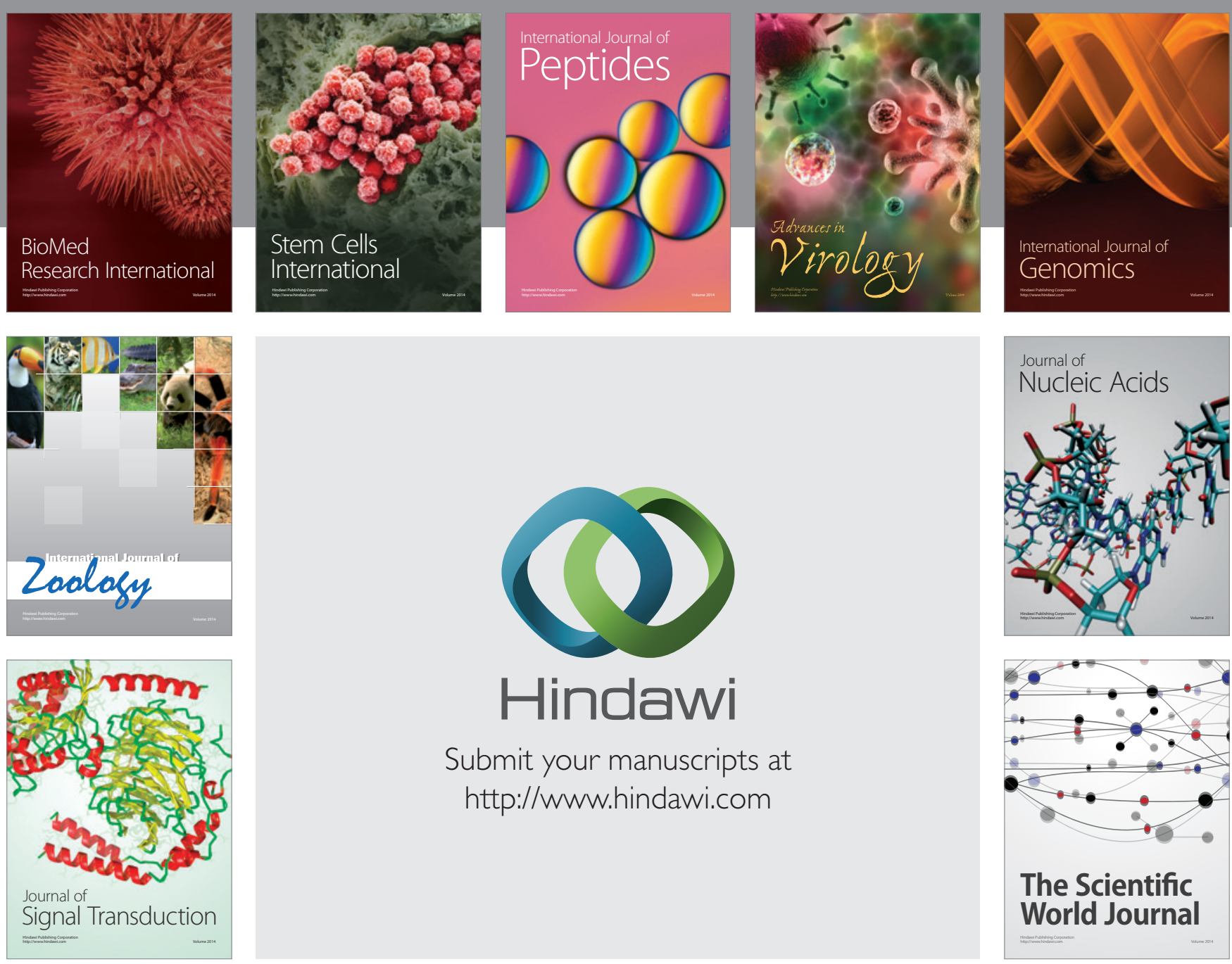

Submit your manuscripts at

http://www.hindawi.com
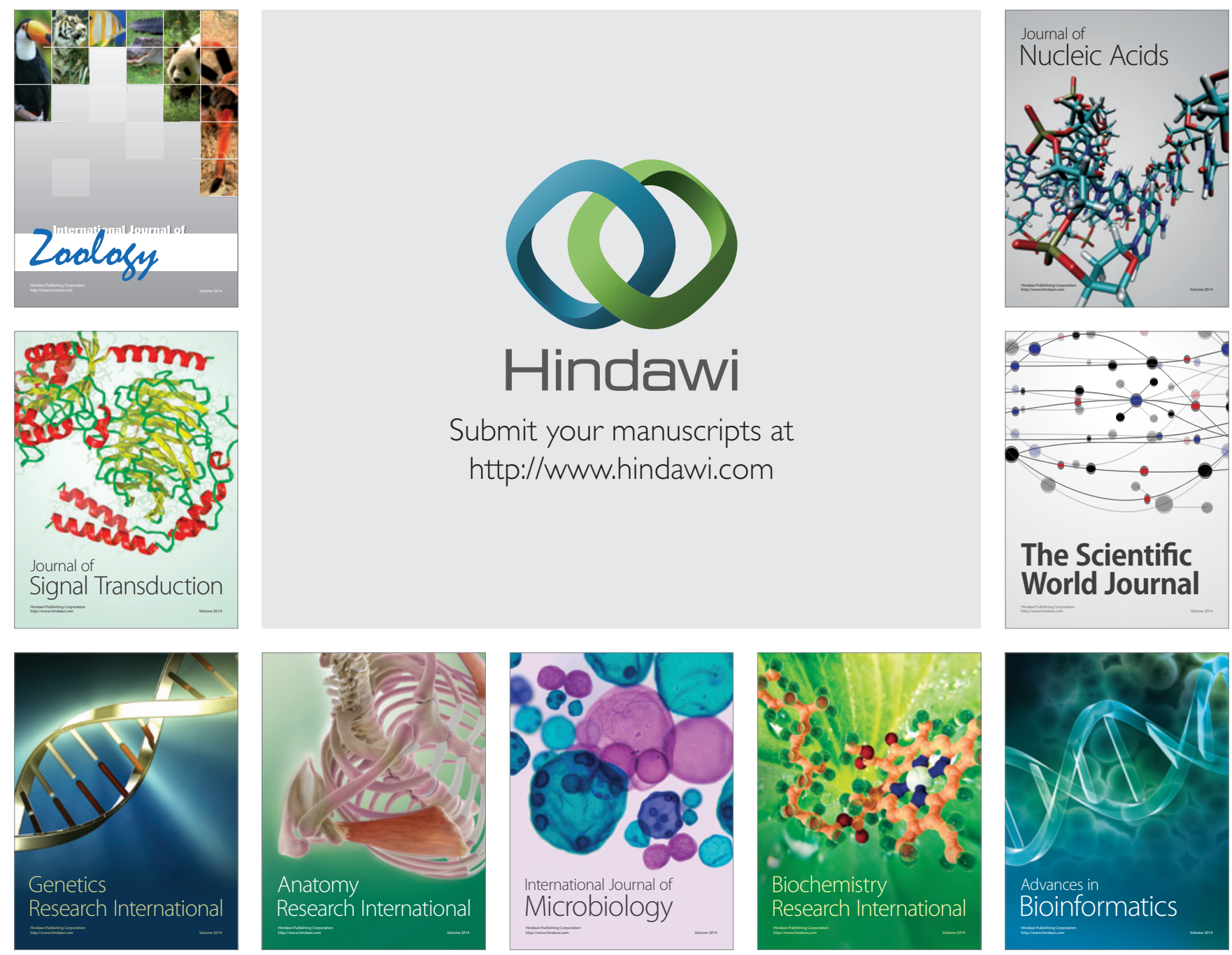

The Scientific World Journal
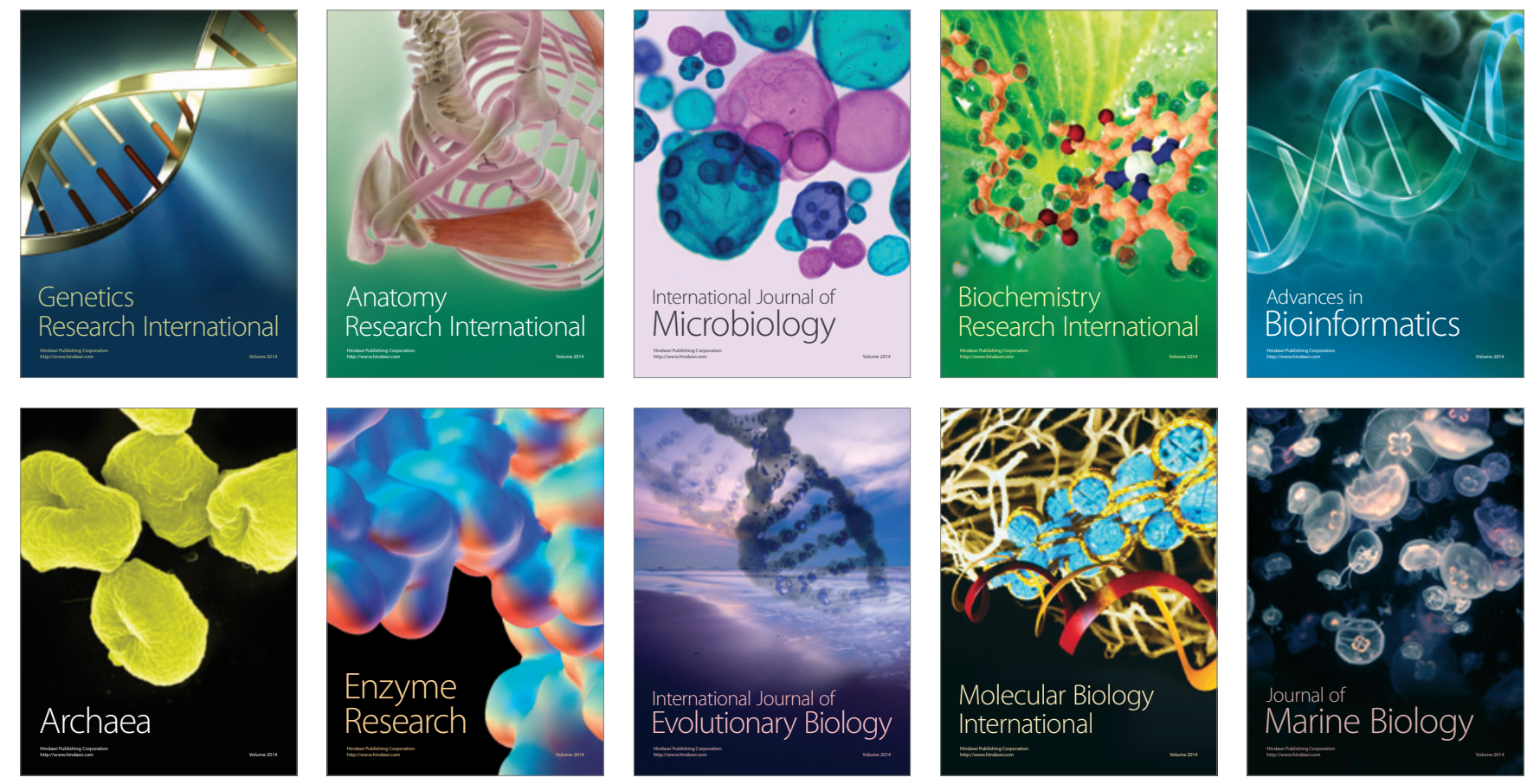